\title{
An old, dear friend has left us: Peter Rosen (1935-2019)
}

\section{Domenico Prisco ${ }^{1}$}

๑) Società Italiana di Medicina Interna (SIMI) 2020

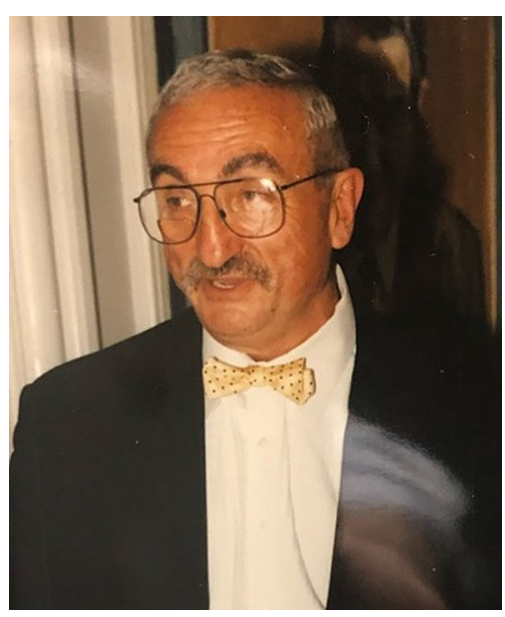

We were deeply saddened by the death of our CoEditorin-Chief Peter Rosen.

Peter was a first-class man, doctor, scientist and editor, who led the Emergency section of our Journal with great commitment, and, as an Emergency doctor, considered by many to be the "inventor" of modern Emergency Medicine, the medical and scientific community has lost one of its most distinguished members. He will be truly missed by our Editorial board, the Italian Society of Internal Medicine, Springer, his friends and family. While we may have lost him, Peter will remain for many a role model in their professional lives due to his commitment to our profession and his strength of character.

In this sad moment, we are not concerned about the future of the Emergency Medicine section of our Journal. Several years ago, due to his declining health, Peter planned to leave the leadership in the capable hands of Bruce Adams who has already been succeeded by Matt Lyon. One of Peter's

Domenico Prisco

domenico.prisco@unifi.it

1 University of Florence, Florence, Italy most significant contributions to the Journal was the Medical Illustrations section which has enjoyed resounding success. Here too, Peter was sure the leadership team was in place and Giorgio Costantino has assumed this important role to ensure its continuity.

This adventure started in 2006 when the Italian Society of Internal Medicine decided to publish an English only Journal. It appointed Gian Franco Gensini as its first Editor-inChief (EiC) who appointed me as chairman of an Operative board created to assist the $\mathrm{EiC}$ in the construction of our new Journal. One of the first questions for the Journal was: should it focus exclusively on Internal Medicine or should it also include Emergency Medicine which in Italy found its start within the specialty of Internal Medicine. The Society chose to include Emergency Medicine and the name of the new Journal became Internal and Emergency Medicine. This all occurred in the context of a partnership between the Tuscan Regional Government and Harvard Medical Faculty Physicians led by Kevin Ban, Leon Sanchez and our dear friend, Peter Rosen. Gian Franco asked Peter to participate in the leadership of the new Journal and he accepted with enthusiasm. Due to the great job he had done, upon becoming the EiC I asked Peter to be Co-editor and he has been a very committed companion to me for several years. We were always tightly aligned and I learned a great deal from his deep knowledge and experience.

Goodbye Peter, you will be missed dearly.

Domenico Prisco, MD

Editor-in-Chief

Internal and Emergency Medicine

Publisher's Note Springer Nature remains neutral with regard to jurisdictional claims in published maps and institutional affiliations. 